\title{
X-linked mixed deafness with perilymphatic gusher
}

INSERM

\section{Source}

INSERM. (1999). Orphanet: an online rare disease and orphan drug data base. $\underline{X-l i n k e d}$ mixed deafness with perilymphatic gusher. ORPHA:383

X-linked mixed deafness with perilymphatic gusher, also known as X-linked deafness type 2 , is a rare form of non-syndromic genetic deafness affecting males and characterized by pathognomonic inner ear anomalies and conductive and profound sensorineural hearing loss. The inner ear anomalies are described as dilatation of the internal auditory meatus and fistulous connection between the cochlear basal turn and internal auditory canal resulting in perilympatic gusher on attempted mobilization of a fixed stapes.

Obligate female carriers may suffer from mild to moderate hearing loss. 